\title{
Distinct metabolic profile according to the shape of the oral glucose tolerance test curve is related to whole glucose excursion: a cross-sectional study
}

\author{
Leonardo de Andrade Mesquita ${ }^{1 *}$ (D) Luciana Pavan Antoniolli ${ }^{1}$, Giordano Fabricio Cittolin-Santos ${ }^{1}$
} and Fernando Gerchman ${ }^{1,2}$

\begin{abstract}
Background: The shapes of the plasma glucose concentration curve during the oral glucose tolerance test are related to different metabolic risk profiles and future risk of type $2 \mathrm{DM}$. We sought to further analyze the relationship between the specific shapes and hyperglycemic states, the metabolic syndrome and hormones involved in carbohydrate and lipid metabolism, and to isolate the effect of the shape by adjusting for the area under the glucose curve.
\end{abstract}

Methods: One hundred twenty one adult participants underwent a 2-h oral glucose tolerance test and were assigned to either the monophasic $(n=97)$ or the biphasic $(n=24)$ group based upon the rise and fall of their plasma glucose concentration. We evaluated anthropometric measures, blood pressure, lipid profile, high-sensitivity C-reactive protein, glycated hemoglobin, insulin sensitivity, beta-cell function, C-peptide, glucagon, adiponectin and pancreatic polypeptide.

Results: Subjects with monophasic curves had higher fasting and 2-h plasma glucose levels, while presenting lower insulin sensitivity, beta-cell function, HDL cholesterol, adiponectin and pancreatic polypeptide levels. Prediabetes and metabolic syndrome had a higher prevalence in this group. Glycated hemoglobin, total cholesterol, triglycerides, highsensitivity C-reactive protein and glucagon were not significantly different between groups. After adjusting for the area under the glucose curve, only the differences in the 1-h and 2-h plasma glucose concentrations and HDL cholesterol levels between the monophasic and biphasic groups remained statistically significant.

Conclusions: Rates and intensity of metabolic dysfunction are higher in subjects with monophasic curves, who have lower insulin sensitivity and beta-cell function and a higher prevalence of prediabetes and metabolic syndrome. These differences, however, seem to be dependent on the area under the glucose curve.

Keywords: Shape of the glucose curve, Area under the glucose curve, Metabolic syndrome, Insulin resistance, Diabetes mellitus

\footnotetext{
* Correspondence: leonardodeamesquita@gmail.com

${ }^{1}$ Faculdade de Medicina da Universidade Federal do Rio Grande do Sul,

Ramiro Barcelos, 2400, Porto Alegre 90035-003, Brazil

Full list of author information is available at the end of the article
}

(c) The Author(s). 2018 Open Access This article is distributed under the terms of the Creative Commons Attribution 4.0 International License (http://creativecommons.org/licenses/by/4.0/), which permits unrestricted use, distribution, and reproduction in any medium, provided you give appropriate credit to the original author(s) and the source, provide a link to the Creative Commons license, and indicate if changes were made. The Creative Commons Public Domain Dedication waiver (http://creativecommons.org/publicdomain/zero/1.0/) applies to the data made available in this article, unless otherwise stated. 


\section{Background}

Criteria for the diagnosis of diabetes mellitus (DM) and at-risk categories of glucose tolerance were established using the oral glucose tolerance test (OGTT) [1]. For this purpose, we currently use only plasma glucose measurements at fasting and $2 \mathrm{~h}$ after ingestion of $75 \mathrm{~g}$ of dextrose. Interestingly, insights into the natural history of glucose tolerance and DM have been derived from data such as the 1 -h plasma glucose (1hPG) concentration [2-5], the relationship between the fasting and 2-h plasma glucose levels [6] and the shape of the glucose concentration curve.

Cross-sectional studies in diverse populations, including Latinos and obese youths [7-14], have assessed the shape of the glucose curve during the 2-h 75 g OGTT and demonstrated patterns associated with insulin resistance and beta-cell dysfunction. Two cohort studies $[15,16]$ showed a different future risk of impaired glucose metabolism and type $2 \mathrm{DM}$ in individuals with distinct shapes of the OGTT glucose curve. Another cohort study [17] found a distinct risk of progression to type $1 \mathrm{DM}$ according to the shape of the glucose curve in subjects with positivity for autoantibodies who were relatives of people with type 1 DM. On the other hand, a cross-sectional study [18] did not find different odds of prediabetes (PDM). Recent research in obese young subjects with distinct shapes of the glucose curve [19] demonstrated differences in free fatty acid response, plasma incretin levels and insulin sensitivity and insulin secretion, which were directly measured using the euglycemic hyperinsulinemic and hyperglycemic clamp techniques, respectively.

In the current study, we examined how the shape of the plasma glucose concentration curve during the OGTT relates to hyperglycemic states, the metabolic syndrome (MetS) and its components, and hormones involved in the carbohydrate and lipid metabolism. We also investigated whether any differences found were dependent only on the shape of the glucose curve.

\section{Methods}

\section{Study design and setting}

We performed a secondary analysis on data obtained between 2008 and 2015 from patients without a previous diagnosis of metabolic syndrome referred for outpatient care to the Metabolism Unit of Hospital de Clínicas de Porto Alegre, a tertiary hospital linked to Universidade Federal do Rio Grande do Sul, a public university in southern Brazil. These patients were enrolled in a cross-sectional study designed to examine the mechanisms and risk factors related to the development of type 2 diabetes and the metabolic syndrome. Additional information regarding the study protocol may be accessed elsewhere [20]. The study protocol was approved by the Institutional Review Board of Hospital de Clínicas de Porto Alegre.

\section{Subjects}

We included in the analysis adult individuals who had a complete, 2-h OGTT with five equally spaced measurements of plasma glucose and insulin concentration. Exclusion criteria included insulin treatment, autoimmune diseases, uncompensated hypo or hyperthyroidism, malignant disease that could affect 5-year survival, stage IV-V chronic kidney disease, HIV infection, pregnancy or lactation, dementia, cirrhosis, hepatitis, glucocorticoid treatment and malnutrition. Application of the criteria above resulted in the exclusion of 41 subjects from an initial population of 228. Of the remaining 187 individuals, 31 were excluded from the analysis due to presenting glucose curve shapes that did not fit criteria for any group. We excluded 35 subjects with DM from the main analysis, because of the possible distortion of the results when including extremes of insulin resistance. The final sample size consisted of 121 individuals (156 for the alternative analysis including subjects with DM).

All subjects provided written informed consent.

\section{Measurements}

We weighed subjects wearing light clothing without shoes. We used a stadiometer to measure height. We calculated body mass index (BMI) dividing the weight in kilograms by the height squared in meters. We measured waist circumference at the midpoint between the lower costal margin and the iliac crest, rounding values to the lowest $0.5 \mathrm{~cm}$. We performed blood pressure (BP) measurements 1 week after the withdrawal of all antihypertensive medications. We measured office BP with an oscillometric monitor device (OMRON H-003D) with the appropriate cuff placed on the right arm of the patient, who had to be sitting for at least $5 \mathrm{~min}$. We used the mean of the last two measurements to estimate systolic and diastolic BP.

Blood samples were taken after a 12-h overnight fast for analysis of plasma lipids (triglycerides, HDL and total cholesterol), glycated hemoglobin (HbA1c), high-sensitivity $\mathrm{C}$-reactive protein (hs-CRP), adiponectin, glucagon, C-Peptide and pancreatic polypeptide (PP). Lipids were determined by an enzymatic method (Siemens ADVIA 1800 Chemistry System), HbA1c by high performance liquid chromatography (Tosoh Plus) and hs-CRP by turbidimetry (Siemens ADVIA 1800 Chemistry System). C-peptide was measured by chemiluminescent microparticle immunoassay (Abbott ARCHITECT; intra-assay coefficient of variation [CV] 2.7-3.2\% and inter-assay $\mathrm{CV}<10 \%)$. The enzyme-linked immunosorbent assay technique was used to determine glucagon (Yanaihara Institute; intra-assay $\mathrm{CV}<5.1 \%$ and inter-assay $\mathrm{CV}<18.9 \%$ ), adiponectin (Invitrogen; intra-assay $\mathrm{CV}<$ $3.84 \%$ and inter-assay CV $<5.50 \%$ ) and PP (Uscn Life Science; intra-assay CV $<10 \%$ and inter-assay $C V<12 \%)$. 
After a 12-h overnight fast, subjects underwent a $75 \mathrm{~g}$ OGTT, with plasma glucose and serum insulin measured at baseline and 30, 60, 90 and $120 \mathrm{~min}$. Plasma glucose was determined by an enzymatic method (Roche Cobas c501) and serum insulin by electrochemiluminescence (Centaur XP; inter-assay CV $<7.0 \%$ ).

\section{Calculations}

We estimated insulin sensitivity with data obtained from the OGTT, using the Gutt insulin sensitivity index [21]:

$$
\begin{gathered}
\text { Gutt index }=\{[(75,000 \mathrm{mg}+(\mathrm{FPG}-2 \mathrm{hPG}) \times 0.19 \times \text { body weight }) \\
\div 120 \mathrm{~min}] \div \text { mean plasma glucose }\} \\
\div \log (\text { mean serum insulin })
\end{gathered}
$$

(FPG: fasting plasma glucose, 2hPG: 2-h plasma glucose; weight should be entered in kilograms, plasma glucose concentration in $\mathrm{mg} / \mathrm{dL}$ and serum insulin levels in $\mu \mathrm{U} / \mathrm{mL})$

This index was the most accurate in determining the presence of metabolic syndrome in our sample [22].

We calculated the insulinogenic index as the ratio between the changes in plasma insulin and glucose concentrations from baseline to $30 \mathrm{~min}$ after the oral glucose challenge, using the same units as in the Gutt index. We used the disposition index, obtained from the multiplication of the Gutt index and the insulinogenic index, to estimate beta-cell function.

\section{Classification of glucose curves}

We classified glucose curves according to previous studies $[8,12-14]$. The "monophasic" $(\mathrm{M})$ curve is defined by a rise in plasma glucose until a peak is reached, followed by a continuous fall. In subjects with a "biphasic" (B) curve, plasma glucose rises until a peak at $30^{\prime}$ or $60^{\prime}$, decreases and increases again from $90^{\prime}$ to $120^{\prime}$. In "triphasic" curves, plasma glucose increases from 0 ' to $30^{\prime}$, decreases from $30^{\prime}$ to $60^{\prime}$, rises again from $60^{\prime}$ to $90^{\prime}$ and falls from $90^{\prime}$ to $120^{\prime}$. In this study, we included triphasic individuals $(n=10)$ in the biphasic group. We deemed a glucose curve shape "unclassifiable" if the difference in plasma glucose between $90^{\prime}$ and $120^{\prime}$ was lower than $0.25 \mathrm{mmol} / \mathrm{L}$ (except for triphasic curves, in which we applied this threshold to the change in plasma glucose between $60^{\prime}$ and $90^{\prime}$ instead). We also excluded subjects with a steady rise in plasma glucose concentration not followed by a fall, who did not fit into the previous groups. Models of each shape are shown in Fig. 1.

\section{Definition of glucose tolerance statuses and metabolic syndrome}

We used the American Diabetes Association criteria (based on FPG and 2hPG) [1] not considering HbA1c to categorize subjects as having normal glucose tolerance (FPG $<5.6 \mathrm{mmol} / \mathrm{L}$ and $2 \mathrm{hPG}<7.8 \mathrm{mmol} / \mathrm{L}$ ),

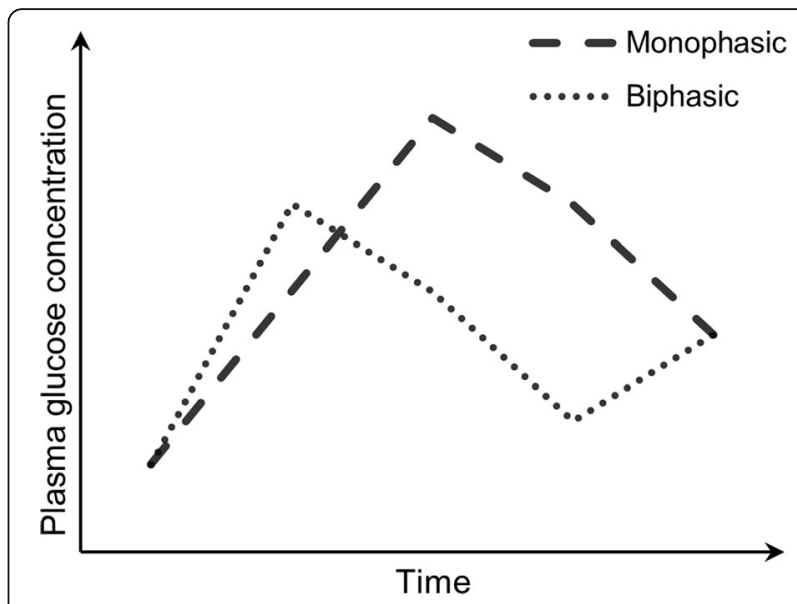

Fig. 1 Shapes of the glucose curve: monophasic (lines) and biphasic (dots). M-shaped triphasic curves (not shown, $n=10$ ) were included in the latter

impaired fasting glucose (FPG 5.6-6.9 mmol/L, 2hPG $<7.8 \mathrm{mmol} / \mathrm{L}$ ), impaired glucose tolerance $(\mathrm{FPG}<$ $5.6 \mathrm{mmol} / \mathrm{L}$, 2hPG $7.8-11.0 \mathrm{mmol} / \mathrm{L}$ ) or diabetes (FPG $\geq 7.0 \mathrm{mmol} / \mathrm{L}$ and/or $2 \mathrm{hPG} \geq 11.1 \mathrm{mmol} / \mathrm{L}$ or use of medication for the control of DM). Subjects with either impaired fasting glucose or impaired glucose tolerance were considered to have prediabetes.

We defined the presence or absence of MetS according to the harmonization of metabolic syndrome criteria from the International Diabetes Federation, the American Heart Association and the National Heart, Lung and Blood Institute, among other organizations [23]. The chosen cut-off points for waist circumference were those of the previous International Diabetes Federation definition. We considered that a subject had MetS if he or she presented at least three of the following: waist circumference $\geq 94 \mathrm{~cm}$ for men or $\geq 80 \mathrm{~cm}$ for women; plasma triglyceride concentration $\geq 1.7 \mathrm{mmol} / \mathrm{L}$ or receiving drug treatment for this abnormality; HDL cholesterol $<1.0 \mathrm{mmol} / \mathrm{L}$ in males or $<1.3 \mathrm{mmol} / \mathrm{L}$ in females or receiving drug treatment for this abnormality; systolic $\mathrm{BP} \geq 130 \mathrm{mmHg}$ or diastolic $\mathrm{BP} \geq 85 \mathrm{mmHg}$ or receiving treatment for previously diagnosed hypertension; FPG $\geq 5.6 \mathrm{mmol} / \mathrm{L}$ or previous diagnosis of type $2 \mathrm{DM}$.

\section{Statistical analysis}

All data are reported in SI units (except for HbA1c, the Gutt, insulinogenic and disposition indices, adiponectin, glucagon and pancreatic polypeptide) and expressed as absolute number (\%), mean \pm standard deviation, or median [P25-P75]. For continuous variables, we assessed the normality of distribution using the Kolgomorov-Smirnov and Shapiro-Wilk tests. We compared demographic characteristics and clinical and laboratory data between groups using the chi-squared test, the Student's t-test or the 
Mann-Whitney U test as appropriate. We adjusted for confounding variables by means of ANCOVA for continuous dependent variables (after log or reciprocal transformation of variables with non-normal distributions) and multiple logistic regression analysis for categorical dependent variables. In these analyses, the shape of the glucose curve was included as categorical independent variable (or factor) and each suspected confounding variable as the covariate in separate models. A $p$-value $<0.05$ was considered statistically significant. Statistical analyses were performed in PASW Statistics 18 (IBM Corporation, Armonk, NY, USA). We used G-Power 3.1 (Heinrich Heine Universität Düsseldorf, Düsseldorf, Germany) to conduct a post-hoc power analysis, in which we determined the $\beta$ error probability of this study and the sample size required to achieve a power of $80 \%$ to detect, in the multiple logistic regression analysis adjusted for glucose AUC, a difference in the prevalence of the metabolic syndrome according to the shape of the glucose curve similar to the one we found in the unadjusted comparison, setting the alpha error rate to 0.05 . We would need a total sample size of 231 subjects in order to reach such power in this analysis.

\section{Results}

Data related to the OGTT and lipid profile were available for all subjects. For some subjects, data was missing as follows: waist circumference ( 1 female for B), blood pressure (2 for $\mathrm{M}, 1$ for $\mathrm{B})$, HbAlc ( 9 for $\mathrm{M}, 5$ for $\mathrm{B}$ ), hs-CRP (13 for M, 3 for B), adiponectin (13 for M, 3 for B), PP (28 for M, 10 for B), C-peptide (21 for M, 5 for B) and glucagon (39 for M, 13 for B).

97 subjects had glucose curves classified as monophasic and 24 as biphasic. The two groups had similar age, sex and ethnic composition. The monophasic group showed a trend toward obesity when compared to the biphasic group, with higher BMI and waist circumference (in both males and females), though these differences did not achieve statistical significance. Details on demographic and anthropometric characteristics are shown in Table 1.

The monophasic group had higher plasma glucose levels at all timepoints and a greater area under the glucose curve (glucose AUC). While fasting and 2-h serum insulin levels and plasma C-peptide concentration were also higher in this group, insulin sensitivity, disposition index, HDL cholesterol, adiponectin and PP levels were lower, and we found no statistically significant difference between groups in hs-CRP, total cholesterol, triglycerides or glucagon levels. The same group also presented a higher prevalence of prediabetes and metabolic syndrome. Data regarding laboratory characteristics are displayed in Table 2 and the prevalence of PDM and MetS is depicted in Fig. 2.

In order to account for the potential confounding effect of the higher waist circumference in the monophasic group, we performed ANCOVA and logistic regression analyses. After adjustment, the differences in 30-min (30minPG), 1-h and 90-min (90minPG) plasma glucose concentration, glucose AUC, Gutt, insulinogenic and disposition indices, and HDL cholesterol levels remained statistically significant, and, while a trend for the monophasic group to have higher 2-h plasma glucose and serum insulin concentrations persisted, the differences did not reach statistical significance. Also, although not statistically significant, we observed a trend for the monophasic curve to predict the presence of the metabolic syndrome (odds ratio $=2.512$ [95\% CI: 0.959-6.585]).

Table 1 Demographic and clinical characteristics according to the shape of the plasma glucose curve

\begin{tabular}{|c|c|c|c|c|}
\hline & & \multicolumn{2}{|c|}{ Shape of the glucose curve } & \multirow[t]{2}{*}{$p$-value } \\
\hline & & Monophasic & Biphasic & \\
\hline \multicolumn{2}{|l|}{ N } & 97 & 24 & - \\
\hline \multicolumn{2}{|l|}{ Age - years } & $51.96 \pm 12.49$ & $51.58 \pm 10.73$ & 0.893 \\
\hline \multicolumn{2}{|l|}{ Female sex - n (\%) } & $73(75.3)$ & $20(83.3)$ & 0.401 \\
\hline \multicolumn{2}{|l|}{ White ethnicity - n (\%) } & $82(87.2)$ & $18(75.0)$ & 0.137 \\
\hline \multicolumn{2}{|l|}{$\mathrm{BMI}-\mathrm{kg} / \mathrm{m}^{2}$} & $31.36 \pm 6.34$ & $29.56 \pm 4.48$ & 0.192 \\
\hline \multirow[t]{3}{*}{ Nutritional status - $\mathrm{n}(\%)^{\mathrm{a}}$} & Lean & $15(15.5)$ & $3(12.5)$ & \multirow[t]{3}{*}{0.140} \\
\hline & Overweight & $28(28.9)$ & $12(50.0)$ & \\
\hline & Obese & $54(55.7)$ & $9(37.5)$ & \\
\hline \multirow[t]{2}{*}{ Waist circumference - $\mathrm{cm}$} & Male & $109.02 \pm 14.98$ & $94.00 \pm 9.06$ & 0.065 \\
\hline & Female & $101.04 \pm 14.42$ & $96.71 \pm 7.37$ & 0.075 \\
\hline \multirow[t]{2}{*}{ Blood pressure - mmHg } & Systolic & $136.93 \pm 23.32$ & $134.24 \pm 18.93$ & 0.608 \\
\hline & Diastolic & $84.05 \pm 13.00$ & $86.63 \pm 11.76$ & 0.387 \\
\hline
\end{tabular}


Table $\mathbf{2}$ Laboratory characteristics according to the shape of the glucose curve

\begin{tabular}{|c|c|c|c|}
\hline & \multicolumn{2}{|l|}{ Shape of the glucose curve } & \multirow[t]{2}{*}{$p$-value } \\
\hline & Monophasic & Biphasic & \\
\hline N & 97 & 24 & - \\
\hline $\mathrm{FPG}-\mathrm{mmol} / \mathrm{L}$ & $5.38 \pm 0.63$ & $5.15 \pm 0.44$ & $0.044^{\mathrm{ab}}$ \\
\hline 30minPG - mmol/L & 9.22 [8.19-10.53] & $7.83[6.76-9.04]$ & $0.001^{\mathrm{ab}}$ \\
\hline $1 \mathrm{hPG}-\mathrm{mmol} / \mathrm{L}$ & $9.83[8.36-11.64]$ & $6.03[5.33-8.71]$ & $<0.001^{\mathrm{ab}}$ \\
\hline $90 \mathrm{~min} P G-\mathrm{mmol} / \mathrm{L}$ & $9.16 \pm 2.40$ & $6.60 \pm 1.87$ & $<0.001^{\mathrm{ab}}$ \\
\hline $2 \mathrm{hPG}-\mathrm{mmol} / \mathrm{L}$ & 8.11 [5.92-9.39] & $6.33[5.07-8.49]$ & $0.028^{\mathrm{ab}}$ \\
\hline Glucose AUC - mmol/L.h & $17.55 \pm 3.49$ & $13.79 \pm 2.99$ & $<0.001^{\mathrm{a}}$ \\
\hline $\mathrm{HbA} 1 \mathrm{c}-\%$ & $5.81 \pm 0.63$ & $5.74 \pm 0.51$ & 0.630 \\
\hline Fasting serum insulin - pmol/L & 66.18 [45.15-100.47] & $44.07[32.10-67.65]$ & $0.016^{\mathrm{ab}}$ \\
\hline 2-h serum insulin - pmol/L & 476.70 [284.07-1017.51] & 301.50 [148.98-470.16] & $0.012^{\mathrm{ab}}$ \\
\hline Gutt index & $3.22[2.43-4.12]$ & $3.95[3.06-5.29]$ & $0.006^{\mathrm{ab}}$ \\
\hline Insulinogenic index & $0.91[0.53-1.48]$ & $1.48[0.70-2.95]$ & $0.017^{\mathrm{ab}}$ \\
\hline Disposition index & $2.99[1.76-5.82]$ & $6.42[3.16-11.55]$ & $0.002^{\mathrm{ab}}$ \\
\hline C-Peptide - nmol/L & $0.76[0.43-0.96]$ & $0.43[0.38-0.70]$ & $0.027^{\mathrm{ab}}$ \\
\hline Glucagon - ng/L & 332.50 [200.00-640.00] & 600.00 [220.00-780.00] & 0.115 \\
\hline Total cholesterol - mmol/L & $5.41 \pm 1.14$ & $5.41 \pm 1.10$ & 0.990 \\
\hline HDL cholesterol - mmol/L & 1.22 [1.01-1.37] & $1.53[1.23-1.76]$ & $<0.001^{\mathrm{ab}}$ \\
\hline Triglycerides - mmol/L & 1.54 [1.04-2.14] & 1.29 [0.80-1.67] & 0.106 \\
\hline hs-CRP - nmol/L & 25.67 [11.90-67.83] & 25.71 [13.48-63.29] & 0.930 \\
\hline Adiponectin - $\mu \mathrm{g} / \mathrm{mL}$ & 11.93 [9.06-15.74] & $15.42[11.24-21.20]$ & $0.018^{\mathrm{ab}}$ \\
\hline$P P-p g / m L$ & 194.20 [103.65-392.15] & 464.45 [204.90-808.15] & $0.049^{\mathrm{ab}}$ \\
\hline
\end{tabular}

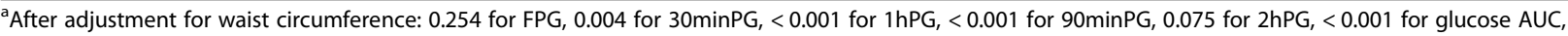
0.311 for fasting serum insulin, 0.050 for 2-h serum insulin, 0.024 for Gutt index, 0.011 for insulinogenic index, 0.012 for disposition index, 0.291 for C-peptide, 0.003 for HDL cholesterol, 0.094 for adiponectin and 0.096 for PP.

${ }^{b}$ After adjustment for glucose AUC: 0.273 for FPG, 0.583 for $30 \mathrm{minPG},<0.001$ for $1 \mathrm{hPG}, 0.348$ for $90 \mathrm{minPG}, 0.049$ for $2 \mathrm{hPG}, 0.379$ for fasting serum insulin, 0.436 for 2 -h serum insulin, 0.767 for Gutt index, 0.464 for insulinogenic index, 0.819 for disposition index, 0.697 for C-peptide, 0.005 for HDL cholesterol, 0.420 for adiponectin and 0.205 for PP

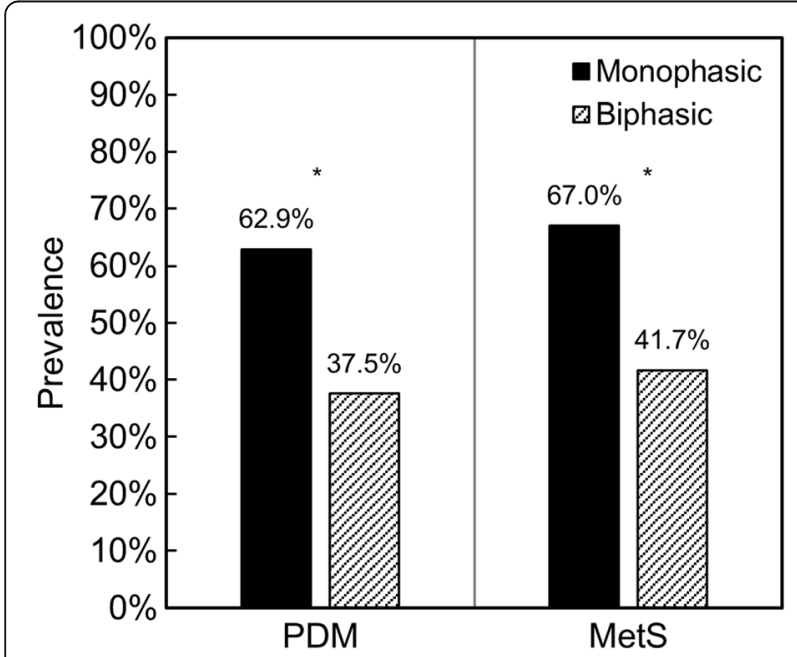

Fig. 2 Prevalence of prediabetes and metabolic syndrome according to the shape of the glucose curve. * PDM: $p=0.024$ (no adjustment), $p=0.120$ (adjusted for waist circumference), $p=0.059$ (adjusted for glucose AUC); MetS: $p=0.022$ (no adjustment), $p=0.061$ (adjusted for waist circumference), $p=0.772$ (adjusted for glucose AUC)
We used the same approach to check whether the findings were related purely to the shape of the glucose curve or dependent on the whole glucose excursion, represented by the glucose AUC. In other words, we would like to know whether two subjects with the same glucose load, i.e. the same glucose AUC in the OGTT, but with different shapes of the glucose curve, would still present a diverse phenotype. Only the differences in 1hPG, 2hPG and HDL cholesterol levels achieved statistical significance after this adjustment. In the model, the monophasic curve showed a trend to have a negative effect on the probability of prediabetes (odds ratio $=0.186[95 \%$ CI: 0.032-1.066]).

Considering data on the OGTT, clinical and laboratory characteristics were available for 35 subjects with DM, whom we did not include in the main analysis because of the possibility of distortion of the results due to their condition as a metabolic extreme, we performed an alternative analysis including those individuals (Additional file 1: Table S1). In this expanded sample of 128 monophasic and 28 biphasic individuals, the comparisons 
yielded mostly similar results to the main analysis. However, the difference in C-peptide levels between the groups did not achieve statistical significance, while the waist circumference (in males) was higher and glucagon levels were lower in the monophasic group before adjustment. Also, we observed statistically significant differences in PP and glucagon, after adjusting for waist circumference, and in waist circumference (in males), FPG, 90minPG, 2-h serum insulin, glucagon, PP and the prevalence of impaired glucose metabolism, after adjusting for glucose AUC. On the other hand, the Gutt index was not significantly different after adjustment for waist circumference and $2 \mathrm{hPG}$ was not significantly different after adjustment for glucose AUC.

\section{Discussion}

This study demonstrates that subjects with monophasic glucose curves in the OGTT, compared with individuals with biphasic curves, have higher fasting plasma glucose and insulin concentrations at all time points. This group has, also, lower insulin sensitivity, insulin secretion, beta-cell function, HDL cholesterol, adiponectin and PP levels. The prevalence of impaired glucose metabolism and metabolic syndrome is also higher in the monophasic group. However, except for 1hPG, 2hPG and HDL cholesterol levels, these differences are not significant after adjusting for glucose AUC, a variable which reflects the whole glucose excursion these individuals are submitted to during the OGTT.

This relationship between the shape of the glucose curve and distinct metabolic profiles found in our study, with the monophasic group being at higher risk for metabolic dysfunction, corroborates the results of previous studies [8, 9, 11-14, 16, 18, 19]. Also, the finding that most differences were not significant after adjustment for glucose AUC is in agreement with the study by Tschritter et al. [8], which, to our knowledge, is the only one to have published results adjusted for glucose AUC, showing that most linear correlations between clinical/ laboratory characteristics and the shape index (a quantitative measure for the shape of the glucose curve) were not significant. This added evidence brings up the hypothesis that the glucose AUC may be a better parameter for predicting metabolic dysfunction.

Surprisingly, even though the monophasic group has a higher prevalence of prediabetes in the unadjusted analysis, we found a trend for the monophasic curve to be associated with a lower probability of impaired glucose metabolism after adjustment for glucose AUC. We believe this may happen due to the diagnosis of prediabetes and diabetes being based on the fasting and 2-h plasma glucose values only [1]. Hence, if we consider subjects with the same glucose AUC, those who have an elevation at $120 \mathrm{~min}$ (biphasic) may be more prone to be diagnosed with impaired glucose metabolism. Nevertheless, since it did not reach statistical significance in the main analysis, this finding needs to be checked in high-powered studies.

In our study, in agreement with previous ones, subjects with biphasic curves displayed a better early-phase insulin secretion (as the insulinogenic index) [8, 9, 12-15]. This finding, along with the greater insulin sensitivity, may explain in part the biphasic curve, as plasma glucose concentration would fall in the early timepoints, followed by a rebound increase in the late OGTT $[8,9,13,14]$. The exact reason for the existence of different shapes of the glucose curve, however, has not been elucidated yet. It may also involve differences in incretin levels and gastrointestinal physiology, requiring specific studies to explore the physiological intricacies behind the different shapes.

The main limitations of our study are the following. First, it has a limited sample size, with which we may not have been able to detect subtler differences between groups, especially in variables with a more significant proportion of missing data, such as the polypeptide hormones. HbA1c and hs-CRP also had a substantial amount of missing data, yet this had not affected the major outcome. As for the main analysis, we found that our study had a power of $53 \%$ and that we would need a total sample of 231 subjects to achieve a power of $80 \%$. Hence, there is a need for studies with a higher sample size to analyze whether the null hypothesis of no difference in most metabolic parameters after controlling for glucose AUC holds true, since we expected to find the same differences despite the adjustment. Second, the cross-sectional design restrains the evaluation of the risk of developing impaired glucose metabolism and metabolic syndrome. Third, we performed a single execution of the OGTT, which does not allow us to make inferences on reproducibility of the shape of the glucose curve in this sample, something other studies [16, 24] have pointed out as relatively poor, and even describing that the combination of shapes of glucose curve from two OGTTs defines groups with different clinical and laboratory characteristics. Also, we estimated insulin sensitivity and beta-cell function with the Gutt and oral disposition indices respectively, instead of directly measuring them through the euglycemic-hyperinsulinemic and hyperglycemic clamp techniques. Nevertheless, previous studies have validated these surrogate measures against the gold standard clamp studies and demonstrated their relationship with clinical outcomes such as the presence of metabolic syndrome and future risk of diabetes $[21,22,25]$. Lastly, our classification of the shapes of the glucose curve - merging the biphasic and triphasic patterns and excluding individuals with a continuously rising plasma glucose concentration - is not based on solid scientific evidence, but is akin to the classification used in previous studies on the subject $[8,13,18,19]$. 
Our study does not evaluate the use of the shape of the glucose curve as a tool in clinical practice. Our search did not return any article about the applicability of this parameter in the clinical setting (e.g. as criteria for differential testing or treatment). While the low reproducibility of this parameter and the neutralization of its impact after adjustment for the glucose AUC may limit its usefulness, specific studies are needed to give a definitive answer.

\section{Conclusions}

The monophasic curve is associated with a greater prevalence of prediabetes and metabolic syndrome, as well as with higher plasma glucose and insulin levels, and lower insulin sensitivity and beta-cell function, but most of the differences found between the groups are driven by the area under the glucose curve. Future studies are necessary to examine the reasons behind the existence of distinct behaviors of the glucose curve and why they are associated with different metabolic and clinical phenotypes.

\section{Additional file}

Additional file 1: Table S1. Demographic, clinical and laboratory characteristics according to the shape of the glucose curve in the full sample (including subjects with DM). (DOCX $19 \mathrm{~kb}$ )

\section{Abbreviations \\ 1hPG: 1-h plasma glucose; 2hPG: 2-h plasma glucose; 30minPG: 30-min plasma glucose; 90minPG: 90-min plasma glucose; B: Biphasic; BMl: Body mass index; BP: Blood pressure; CV: Coefficient of variation; DM: Diabetes mellitus; FPG: Fasting plasma glucose; glucose AUC: Area under the glucose curve; HbA1c: Glycated hemoglobin; hs-CRP: High-sensitivity C-reactive pro- tein; M: Monophasic; MetS: Metabolic syndrome; OGTT: Oral glucose tolerance test; PDM: Prediabetes mellitus; PP: Pancreatic polypeptide}

\section{Acknowledgements}

We would like to thank Dr. Ralph A. DeFronzo for reviewing the preliminary manuscript and making valuable comments. We would also like to recognize the work of the following persons, who integrate (or integrated) our research group and helped in the execution of the study: Anize D. von Frankenberg, Bárbara L. Nedel, Carina de Araújo, Giovana F. Piccoli, Letícia M. T. Silva, Lucas E. Gatelli, Mayara A. Beer, Monique de M. Machado, Raquel C. Fitz, Rodrigo S. de S. Marques, Tássia C. Pazinato and Vanessa Piccoli.

\section{Funding}

This work was supported by the Research Support Foundation of the State of Rio Grande do Sul (Fundação de Amparo à Pesquisa do Estado do Rio Grande do Sul - FAPERGS; grant number: 5989.284.18921.12062013), the Brazilian National Council for Scientific and Technologic Development (Conselho Nacional de Desenvolvimento Científico e Tecnológico - CNPq; grant number: 486802/2013-2) and the Hospital de Clínicas de Porto Alegre Research and Events Incentive Funds (Fundo de Incentivo à Pesquisa e Eventos - FIPE-HCPA). The funding sources had no role in the design of the study, collection, analysis and interpretation of data, nor in the drafting of the manuscript.

\section{Availability of data and materials}

The datasets used and/or analysed during the current study are available from the corresponding author on reasonable request.

\section{Authors' contributions}

LdAM designed the analysis, interpreted the data and was a major contributor in writing the manuscript. LPA participated in the acquisition, sorting and analysis of data. GFCS contributed in drafting the manuscript. FG designed the original study and contributed in every stage of the present analysis. All authors read and approved the final manuscript.

\section{Ethics approval and consent to participate}

The study protocol was approved by the Institutional Review Board of Hospital de Clínicas de Porto Alegre and all subjects provided written informed consent.

\section{Consent for publication}

Not applicable.

\section{Competing interests}

The authors declare that they have no competing interests.

\section{Publisher's Note}

Springer Nature remains neutral with regard to jurisdictional claims in published maps and institutional affiliations.

\section{Author details}

${ }^{1}$ Faculdade de Medicina da Universidade Federal do Rio Grande do Sul, Ramiro Barcelos, 2400, Porto Alegre 90035-003, Brazil. ²Serviço de Endocrinologia do Hospital de Clínicas de Porto Alegre, Ramiro Barcelos, 2350, Porto Alegre 90035-903, Brazil.

Received: 26 March 2018 Accepted: 9 August 2018

Published online: 16 August 2018

\section{References}

1. Classification and diagnosis of diabetes. Diabetes Care [Internet]. 2017;40: S11-24. Available from: http://care.diabetesjournals.org/lookup/doi/10.2337/ dc17-S005

2. Abdul-Ghani MA, Abdul-Ghani T, Ali N, Defronzo RA. One-hour plasma glucose concentration and the metabolic syndrome identify subjects at high risk for future type 2 diabetes. Diabetes Care. 2008;31:1650-5. [Internet] Available from: http://www.ncbi.nlm.nih.gov/pubmed/18487478\%5Cnhttp:// www.pubmedcentral.nih.gov/articlerender.fcgi?artid=PMC2494641

3. Bergman M, Chetrit A, Roth J, Dankner R. One-hour post-load plasma glucose level during the OGTT predicts mortality: observations from the Israel Study of Glucose Intolerance, Obesity and Hypertension. Diabet Med. 2016;33:1060-6. [Internet] [cited 2018 Jan 22] Available from: http://doi. wiley.com/10.1111/dme.13116

4. Bergman M, Chetrit A, Roth J, Jagannathan R, Sevick M, Dankner R. One-hour post-load plasma glucose level during the OGTT predicts dysglycemia: observations from the 25 year follow-up of the Israel study of glucose intolerance, obesity and hypertension. Diabetes Res Clin Pract. 2016;120:221-8. [Internet]. Elsevier. Available from: https://doi.org/10.1016/j.diabres.2016.08.013

5. Pareek M, Bhatt DL, Nielsen ML, Jagannathan R, Eriksson K-F, Nilsson PM, et al. Enhanced predictive capability of a 1-hour oral glucose tolerance test: A prospective population-based cohort study. Diabetes Care. 2018;41:171 LP177. [Internet]. Available from: http://care.diabetesjournals.org/content/41/1/ 171.abstract

6. Abdul-Ghani MA, Williams K, DeFronzo R, Stern M. Risk of progression to type 2 diabetes based on relationship between postload plasma glucose and fasting plasma glucose. Diabetes Care. 2006;29:1613-8. [Internet] [cited 2017 May 2]. Available from: http://care.diabetesjournals.org/cgi/doi/10. 2337/dc05-1711

7. Fuchigami M, Nakano H, Oba K, Metori S. Oral glucose tolerance test using a continuous blood sampling technique for analysis of the blood glucose curve (article in Japanese). Japanese J Geriatr. 1994:31:518-24.

8. Tschritter O, Fritsche A, Shirkavand F, Machicao F, Häring H, Stumvoll M. Assessing the shape of the glucose curve during an oral glucose tolerance test. Diabetes Care. 2003;26:1026-33.

9. Kanauchi M, Kimura K, Kanauchi K, Saito Y. Beta-cell function and insulin sensitivity contribute to the shape of plasma glucose curve during an oral glucose tolerance test in non-diabetic individuals. Int J Clin Pract. 2005;59: 427-32. [Internet] [cited 2017 Feb 13]. Available from: https://onlinelibrary. wiley.com/doi/abs/10.1111/j.1368-5031.2005.00422.x

10. Zhou W, Gu Y, Li H, Luo M. Assessing 1-h plasma glucose and shape of the glucose curve during oral glucose tolerance test. Eur J Endocrinol [Internet]. 2006;155:191-7. Available from: http://www.eje-online.org/ content/155/1/191.abstract 
11. Tura A, Morbiducci U, Sbrignadello S, Winhofer Y, Pacini G, Kautzky-Willer A. Shape of glucose, insulin, C-peptide curves during a 3-h oral glucose tolerance test: any relationship with the degree of glucose tolerance? AJP Regul Integr Comp Physiol [Internet]. 2011;300:R941-8. Available from: http://ajpregu.physiology.org/cgi/doi/10.1152/ajpregu.00650.2010

12. Nolfe G, Spreghini MR, Sforza RW, Morino G, Manco M. Beyond the morphology of the glucose curve following an oral glucose tolerance test in obese youth. Eur J Endocrinol [Internet]. 2012;166:107-14. Available from: http://www.eje-online.org/content/166/1/107.abstract

13. Kim JY, Coletta DK, Mandarino $\amalg$, Shaibi GQ. Glucose response curve and type 2 diabetes risk in Latino adolescents. Diabetes Care [Internet]. 2012;35: 1925-30. Available from: http://care.diabetesjournals.org/cgi/doi/10.2337/ dc11-2476

14. Bervoets $L$, Mewis A, Massa $G$. The shape of the plasma glucose curve during an oral glucose tolerance test as an indicator of beta cell function and insulin sensitivity in end-pubertal obese girls. Horm Metab Res. 2015;47: 445-51. [Internet]. Germany. Available from: http://www.thieme-connect.de/ DOI/DOI?10.1055/s-0034-1395551

15. Abdul-Ghani MA, Lyssenko V, Tuomi T, DeFronzo RA, Groop L. The shape of plasma glucose concentration curve during OGTT predicts future risk of type 2 diabetes. Diabetes Metab Res Rev. 2010;26:280-6. [Internet] [cited 2017 Feb 13]. Available from: https://onlinelibrary.wiley.com/doi/abs/10. 1002/dmrr.1084

16. Manco M, Nolfe G, Pataky Z, Monti L, Porcellati F, Gabriel R, et al. Shape of the OGTT glucose curve and risk of impaired glucose metabolism in the EGIR-RISC cohort. Metabolism. 2017;70:42-50. [Internet] . Elsevier. Available from: http://dx.doi.org/10.1016/j.metabol.2017.02.007

17. Ismail HM, Xu P, Libman IM, Becker DJ, Marks JB, Skyler JS, et al. The shape of the glucose concentration curve during an oral glucose tolerance test predicts risk for type 1 diabetes. Diabetologia. 2018;61:84-92. [Internet]. Springer Berlin Heidelberg. [cited 2017 Oct 29]. Available from: http://link. springer.com/10.1007/s00125-017-4453-6

18. Chung ST, Ha J, Onuzuruike AU, Kasturi K, Galvan-De La Cruz M, Bingham BA, et al. Time to glucose peak during an oral glucose tolerance test identifies prediabetes risk. Clin Endocrinol (Oxf). 2017;87:484-91. [Internet]. Available from: http://doi.wiley.com/10.1111/cen.13416

19. Kim JY, Michaliszyn SF, Nasr A, Lee SJ, Tfayli H, Hannon T, et al. The shape of the glucose response curve during an oral glucose tolerance test heralds biomarkers of type 2 diabetes risk in obese youth. Diabetes Care [Internet]. 2016;39:1431-9. Available from: http://care.diabetesjournals.org/content/39/ 8/1431.abstract

20. von Frankenberg AD, do Nascimento FV, Gatelli L, Nedel BL, Garcia SP, de Oliveira CS, et al. Major components of metabolic syndrome and adiponectin levels: a cross-sectional study. Diabetol Metab Syndr [Internet] 2014;6:26. Available from: http://dmsjournal.biomedcentral.com/articles/10. 1186/1758-5996-6-26

21. Gutt M, Davis CL, Spitzer SB, Llabre MM, Kumar M, Czarnecki EM, et al. Validation of the insulin sensitivity index (ISI0,120): Comparison with other measures. Diabetes Res Clin Pract. 2000;47:177-84. [Internet]. Elsevier. [cited 2017 Feb 13]. Available from: http://www.diabetesresearchclinicalpractice. com/article/S0168822799001163/fulltext

22. Antoniolli LP, Piccoli V, Beer MA, Nedel BL, Pazinato TC, Gatelli LE, et al. Accuracy of insulin resistance indices for metabolic syndrome in a population with different degrees of glucose tolerance. Diabetol Metab Syndr. 2015;7:51. [Internet]. BioMed Central. Available from: http://www. embase.com/search/results?subaction=viewrecord\&from=export\&id= L615888373\%5Cnhttp://sfx.library.uu.nl/utrecht?sid=EMBASE\&issn= 17585996\&id=doi:\&atitle=Accuracy+of+insulin+resistance+indices+for +metabolic+syndrome+in+a+population+with+different+de

23. KGMM A, Eckel RH, Grundy SM, Zimmet PZ, Cleeman II, Donato KA, et al. Harmonizing the metabolic syndrome: A joint interim statement of the international diabetes federation task force on epidemiology and prevention; National heart, lung, and blood institute; American heart association; World heart federation; International. Circulation [Internet]. 2009; 120:1640-5. Available from: http://circ.ahajournals.org/content/120/16/1640. abstract\%5Cnhttp://circ.ahajournals.org/content/120/16/1640.full.pdf

24. Kramer CK, Vuksan V, Choi H, Zinman B, Retnakaran R. Emerging parameters of the insulin and glucose response on the oral glucose tolerance test: Reproducibility and implications for glucose homeostasis in individuals with and without diabetes. Diabetes Res Clin Pract. 2014;105:88-95. [Internet].
Elsevier. [cited 2017 Feb 14]. Available from: http://www. diabetesresearchclinicalpractice.com/article/S016882271400206X/fulltext

25. Utzschneider KM, Prigeon RL, Faulenbach MV, Tong J, Carr DB, Boyko EJ, et al. Oral Disposition Index Predicts the Development of Future Diabetes Above and Beyond Fasting and 2-h Glucose Levels. Diabetes Care [Internet]. 2009;32:335 LP-341. Available from: http://care.diabetesjournals.org/content/ 32/2/335.abstract

\section{Ready to submit your research? Choose BMC and benefit from:}

- fast, convenient online submission

- thorough peer review by experienced researchers in your field

- rapid publication on acceptance

- support for research data, including large and complex data types

- gold Open Access which fosters wider collaboration and increased citations

- maximum visibility for your research: over $100 \mathrm{M}$ website views per year

At $\mathrm{BMC}$, research is always in progress.

Learn more biomedcentral.com/submissions 